 \\ Лингвокогнитивное моделирование предвыборного дискурса США в период глобальной пандемии
}

\author{
Касимова Д. И., Григорьева Л. М.
}

\begin{abstract}
Аннотация. Цель исследования - определить когнитивные модели, используемые в предвыборных речах кандидатов на пост президента США в 2020 году, и выявить возможное смещение ценностных ориентиров электората в кризисный период глобальной пандемии. Языковым материалом количественного и качественного анализа послужили корпусы речей Дональда Трампа и Джозефа Байдена, составляющие в сумме около 479 тыс. токенов. Научная новизна исследования заключается в том, что впервые было выявлено и проанализировано смещение превалирующей когнитивной модели актуального политического дискурса США в свете кризисных событий. Результаты исследования позволяют предположить, что сдвиг приоритетной когнитивной модели в пользу Заботливого Родителя (при ранее доминирующей модели Строгого Отца) произошёл на фоне разворачивающейся глобальной пандемии.
\end{abstract}

\section{EN Linguocognitive Modelling of the US Election Discourse during the Global Pandemic}

\begin{abstract}
Kasimova D. I., Grigoryeva L. M.
Abstract. The research aims to determine the cognitive models used in election campaign speeches by the 2020 US presidential candidates and identify a possible shift in the electorate's value orientations during the crisis period of the global pandemic. Donald Trump's and Joseph Biden's speech corpora, totalling approximately 479 thousand tokens, served as linguistic material for a quantitative and qualitative analysis. The research is novel in that it is the first to identify and analyse the shift of the prevailing cognitive model of the current US political discourse in the light of crisis events. The research findings make it possible to suggest that the shift of the priority cognitive model in favour of the Nurturant Parent Model (with the Strict Father Model being previously dominant) occurred amidst the unfolding global pandemic.
\end{abstract}

\section{Введение}

В настоящей работе современный политический дискурс рассматривается как лингвосоциальный феномен, в той или иной степени охватывающий население различных стран. Так, согласно Ф. де Соссюру (1999), моделирующими факторами политического дискурса являются языковые ценности, социальные нормы и практики, «ограничиваемые структурами власти и историческими процессами, находящимися под их влиянием» (с. 426). На сегодняшний день политический дискурс широко реализуется в смежном поле массмедийной дискурсивной практики, в частности благодаря развитию и популяризации социальных сетей, к которым политики нередко прибегают с целью осуществления прямого контакта с гражданами, повышения эффективности персуазивной коммуникации (Штейнман, 2012).

В свете вышесказанного становится очевидна двунаправленная природа политического дискурса, под которой мы понимаем то, что, с одной стороны, политический дискурс формирует превалирующие национальные ценности, социальные практики, следует устоявшимся социальным нормам и создаёт прецеденты и, с другой стороны, отражает актуальные национальные ценности, убеждения и т.д. Таким образом, анализ современного политического дискурса позволяет выявить специфические этнокультурные, социальные ориентиры и отследить тенденцию их изменений (Volkova, 2020).

Актуальность исследования обусловлена необходимостью отразить лингвокогнитивные изменения в моделировании современного предвыборного дискурса США для определения смещения национальных ценностей и убеждений электората. Современный политический дискурс отличается своей конфликтогенной 
природой. Так, исследования особенностей моделирования дискурса, в частности предвыборного дискурса США, позволяют повысить эффективность межкультурной коммуникации в общественно-политическом аспекте и снизить ее конфликтогенность. Подобный анализ национальных ценностных ориентиров представляет особый интерес в связи с текущими глобальными событиями, связанными с мировой пандемией. Предвыборная избирательная кампания в США 2020 года разворачивалась на фоне мирового и национального кризиса, что обуславливает высокую актуальность лингвокогнитивного анализа политического дискурса в указанном контексте.

В рамках исследования дискурса мы придерживаемся синтезированного подхода, включающего в себя компьютерную обработку языкового материала с целью проведения статистического анализа, а также когнитивную интерпретацию полученных данных, что позволяет реализовать качественный анализ дискурсивной практики. Таким образом, комбинация двух подходов существенно повышает валидность проводимого исследования. Выбор когнитивного подхода к исследованию дискурса обусловлен его антропоцентричной направленностью изучения процесса речепорождения.

Для достижения заявленной цели исследования необходимо решить следующие задачи: во-первых, выявить и описать превалирующие когнитивные модели политического дискурса США; во-вторых, сформировать индивидуальные корпусы концептов, использованные кандидатами на пост президента США в 2020 году; в-третьих, определить доминирующие когнитивные модели в предвыборных речах Д. Трампа и Дж. Байдена посредством качественного и количественного анализа; в-четвертых, выявить и интерпретировать изменения в лингвокогнитивном моделировании актуального предвыборного дискурса в период глобальной пандемии.

Решение поставленных задач обусловливает выбор методов исследования: гипотетико-дедуктивный метод, количественный подсчет, метод когнитивного анализа дискурса.

В статье подвергаются лингвокогнитивному анализу публичные речи, заявления, стенограммы теледебатов и интервью, опубликованные в рамках предвыборной кампании в США 2020 г. Так, на основе опубликованных материалов были составлены корпусы речей Дж. Байдена и Д. Трампа, каждый из которых состоит из 246342 и 232492 токенов соответственно. Основными источниками языковых данных послужили веб-ресурсы www.rev.com и factba.se.

Для загрузки и проведения статистического анализа корпусов речей политиков использовался язык программирования Python 3.6, в частности такие библиотеки, как selenium, nltk, PyMorphy и др.

Теоретическую базу исследования составляют работы отечественных и зарубежных ученых, чьи труды посвящены проблемам когнитивной метафоры и метафорическому моделированию, - М. Джонсон, Дж. Лакофф, А. Н. Баранов, Ю. Н. Караулов, Е. С. Кубрякова, В. Н. Телия, А. П. Чудинов и др.

В данной работе на материале собранных корпусов речей мы определили доминирующие когнитивные модели, используемые кандидатами на пост президента США с целью подтвердить или опровергнуть гипотезу о потенциальном изменении превалирующих национальных американских ценностей и убеждений в период пандемии и связанного с ней кризиса.

Практическая значимость исследования состоит в том, что его результаты могут быть использованы при разработке курсов и спецкурсов по когнитивной и политической лингвистике, теории метафоры и когнитивного моделирования.

\section{Основная часть}

В когнитивной лингвистике метафору относят к «важному средству воздействия на интеллект, чувства и волю адресата» (Чудинов, 2001, с. 12). Анализ процесса метафоризации позволяет описать как индивидуальную лингвокультурную проекцию мира, так и групповое, национальное самосознание (Баранов, 2004). В процессе метафоризации человек структурирует и подвергает анализу окружающую его действительность, в связи с чем анализ метафор на материале публичных речей кандидатов в рамках предвыборной кампании позволяет выявить глубинные механизмы и средства моделирования политического дискурса (Lakoff, 2008).

С целью анализа превалирующих когнитивных моделей в предвыборном дискурсе США мы обратились к метафоре «нация-семья», «государство-семья» по причине конститутивной и универсальной природы данной метафоры. Широкое распространение метафоры семьи обусловлено социальной особенностью человеческого генотипа, для которого характерен долгий период детства, а семье отводится важная роль во всех известных мировых культурах.

В качестве теоретической основы данной статьи используется теория концептуальных метафор Дж. Лакоффа, а также предложенная им система когнитивных моделей, подробно изложенная в работе “Moral Politics: How Liberals and Conservatives Think” (Lakoff, 1996). В своей книге Дж. Лакофф пишет о том, что человек воспринимает такую большую общность людей как государство в рамках минимальной единицы общности, которая наиболее хорошо знакома ему с самого детства, - семьи.

Как и семья, метафорическое восприятие государства также подвергается иерархическому строю, где граждане выступают в роли детей, а глава государства - в роли родителя. В той связи, что когнитивная модель представляет собой некую глубоко укоренившуюся структурированную систему ценностей, ориентиров и ожиданий индивида, когнитивная модель позволяет проецировать нравственные законы, берущие начало в семье, на законы, действующие в государственной политике. Дж. Лакофф выделяет два основных типа когнитивных моделей в политическом дискурсе США - модели «Строгого Отца» и «Заботливого Родителя». 
Согласно Дж. Лакоффу, модель Заботливого Родителя характеризуется включением социальной системы ценностей, где поощряется помощь родителей детям, что проецируется на широкое распространение социальной поддержки граждан, преимущественно незащищенных слоев населения; особое значение приобретает безопасность, которая включает в себя не только защиту от очевидных угроз, но также и защиту экологии, борьбу с гендерным, национальным и классовым неравенством. Модель Заботливого Отца также предполагает гибкую систему социальных лифтов для всех слоёв населения.

По Дж. Лакоффу, в модели Строгого Отца распространены такие ценности, как самодисциплина, конкуренция, финансовая независимость детей от родителей и бережливость. Таким образом, социальная поддержка граждан преимущественно игнорируется в риторике Строгого Отца. В рамках данной модели внешний мир за пределами семьи (государства) прежде всего предстаёт потенциально опасным местом, откуда исходят угрозы внутреннему благосостоянию граждан, что прямым образом отражается на миграционной политике государства. Устройство общества в модели Строгого Отца подчиняется строгой иерархии, что также оправдано моральными ценностями.

Дж. Лакофф в своей концепции модели Строгого Отца также допускает, что роль главы семейства может выполнять и Строгая Мать, образ которой достаточно часто встречается в неполных семьях. Однако в связи с тем, что описываемая модель призвана быть некой обобщённой и идеализированной когнитивной иллюстрацией, в ядре модели фигурирует именно Строгий Отец.

Безусловно, в таком сложном и многокомпонентном феномене, как политический дискурс, неизбежно встречаются отклонения от приоритетной когнитивной модели в риторике политиков, однако существует ряд вопросов, по которым две обозначенные модели кардинально расходятся. К подобному роду маркерных вопросов политической риторики относится проблема миграционной политики, которая рассматривается в настоящей работе.

Так, мы провели качественный анализ собранного языкового материала с целью выявить и описать превалирующие модели Д. Трампа и Дж. Байдена в рамках предвыборной кампании. Результаты лингвокогнитивного анализа показали, что Д. Трамп строит свою предвыборную риторику в заданных ценностных ориентирах Строгого Отца. Наиболее ярко риторика Строгого Отца реализуется в миграционном вопросе, где политик стремится защитить граждан от пагубного воздействия внешнего опасного мира, в частности в лице мигрантов.

"Now the wall is great. It goes down deep and it goes up high. No more tunneling. We're bringing our jobs, our factories, our troops back home in the USA where they belong” (Donald Trump..., 2022). / «Теперь стена отличная. Она опускается далеко вниз и высоко поднимается. Больше никаких подкопов. Мы возвращаем наши рабочие места, наши фабрики, наши войска домой в США, где им и место» (здесь и далее перевод сделан авторами статьи. - Д. К., Л. Г.).

"Under my leadership we achieved the most secure border, Southern border in US history" (Donald Trump..., 2022). / «Под моим руководством мы смогли сделать наши границы, южные границы, самыми безопасными в истории США».

"He will do things that will destroy our country. This would trigger a tsunami of illegal immigration. They want to have free healthcare for all. Free education for all. Everybody gets a lawyer" (Donald Trump..., 2022). / «Он сделает такое, что разрушит нашу страну. Его действия вызовут иунами нелегальной иммиграции. Они хотят сделать медицину бесплатной для всех. Бесплатное образование для всех. Каждого обеспечить адвокатом».

Вышеописанные фрагменты из публичных выступлений Д. Трампа наглядно демонстрируют стремления политика оградить нацию и страну от пагубного и деструктивного, по мнению кандидата, влияния мигрантов. Так, Трамп заявляет, что его оппоненты хотят предоставить бесплатные медицинские услуги, образование и юридическую поддержку для всех граждан, включая мигрантов, что в корне противоречит ценностям Строгого Отца, где существует строгая иерархическая система с неоспоримым приоритетом на доступ к материальным благам. Трамп, в свою очередь, лоббирует проект возведения стены у границы с Мексикой для обеспечения национальной безопасности США. Таким образом, возведение стены для защиты от миграционного потока является яркой иллюстрацией ценностных ориентиров модели Строгого Отца.

В риторике Дж. Байдена, напротив, отчётливо прослеживаются ценности Заботливого Родителя в миграционном вопросе:

"We must seek not to build walls but bridges; we must seek not to have our fist clenched, but our arms open. We have to seek not to tear each other apart but seek to come together" (Joe Biden..., 2022). / «Мы должны стремиться возводить не стены, но мосты; мы должны стремиться не сжимать кулаки, но раскрывать объятия. Мы должны стремиться не разлучать друг друга, но объединяться».

"We're all equal. We're all deserving. I am running to be a President for all Americans - including 3 million American citizens living in Puerto Rico. I'm not going to steal the money that's desperately needed for reconstruction on the Island in order to build a wall along the border that does nothing to keер Americans safe” (Joe Biden..., 2022). / «Мы все равны. Мы все этого заслуживаем. Я баллотируюсь на пост президента от всех американцев, включая 3 миллиона американских граждан, проживающих в Пуэрто-Рико. Я не собираюсь красть деньги, которые так необходимы для восстановления острова, чтобы построить стену вдоль границы, которая ничего не сделает для обеспечения безопасности американцев».

"Our Statue of Liberty, not very far away from here, says - invites us to welcome the tired, the poor, the huddled masses yearning to breathe free” (Joe Biden..., 2022). / «Наша Статуя Свободы, которая недалеко отсюда, призывает нас приветствовать толпы уставших, бедных и жаждущих свободы людей».

“That's why I've laid out extensive plans that demonstrate how we're going to use every tool at our disposal to take on the inequities that hurt Hispanic communities - by: investing in economic mobility... and finally building an immigration 
system that treats people with dignity and is true to American values" (Joe Biden..., 2022). / «Вот почему я изложил далеко идущие планы, демонстрирующие, как мы собираемся использовать все имеющиеся в нашем распоряжении инструменты, чтобы бороться с несправедливостью, наносящей ущерб латиноамериканским сообществам, путем инвестирования в экономическую мобильность... и, наконец, создания иммиграционной системы, которая относится к людям достойно, что соответствует нашим американским ценностям».

Согласно концепции Дж. Лакоффа, Дж. Байден моделирует свой предвыборный дискурс в рамках Заботливого Родителя, так как в его риторике мигранты не ассоциируются с потенциальной угрозой, но с новыми членами американского общества, претендующими на равный доступ к национальным благам (“We're all equal. We're all deserving”). Более того, Байден также заявляет, что предоставление мигрантам возможности полноценно интегрироваться в общество соответствует американским ценностям (“finally building an immigration system that treats people with dignity and is true to American values").

Мы также провели количественный анализ рассматриваемых предвыборных корпусов речей с целью выявления при помощи Руthon 3.6 превалирующих концептов, использованных кандидатами. Ниже представлена гистограмма с наиболее распространенными концептами в речах Д. Трампа и Дж. Байдена (см. Рис. 1).

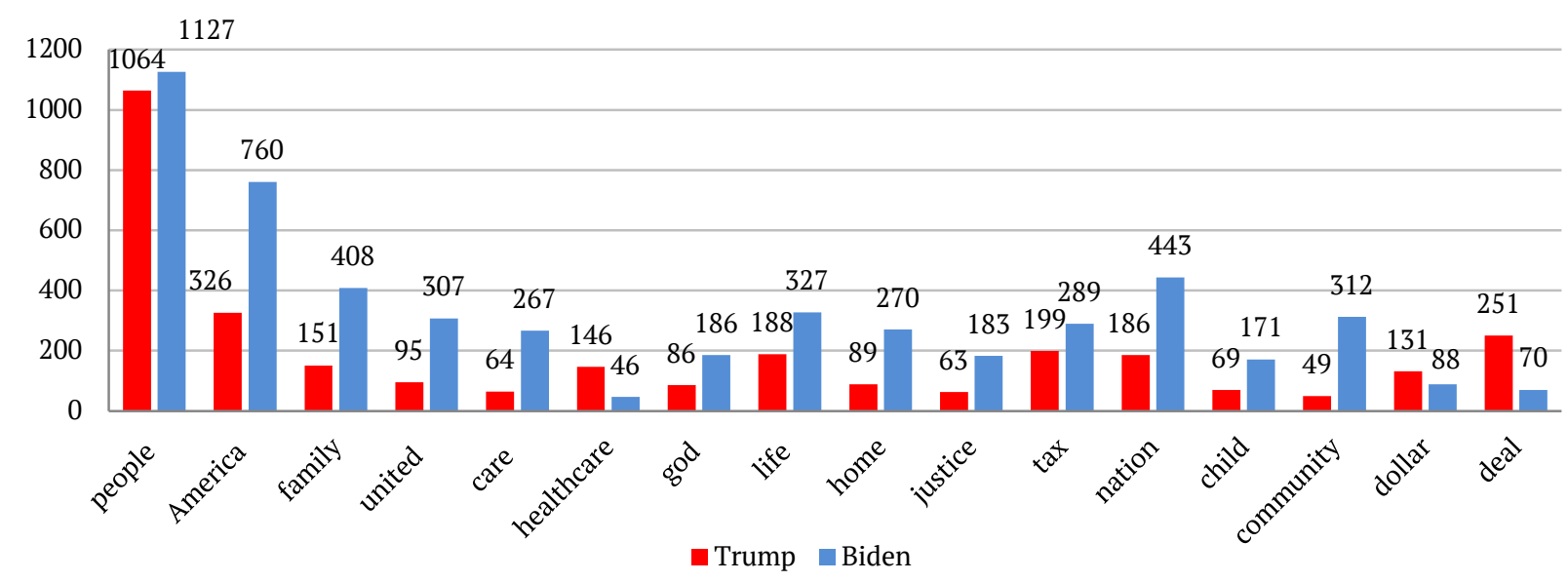

Рисунок 1. Наиболее частотные концепы в предвыборном дискурсе Д. Трампа и Дж. Байдена

Гистограмма демонстрирует разницу в частоте употребления наиболее популярных для обоих корпусов концептов, таких как “people, America, family, united, care, healthcare, god, life, home, justice, tax, nation, child, community, dollar, deal”. Так, наибольший разрыв в частоте употребления концептов в корпусах Дж. Байдена и Д. Трампа встречается в концептах “community” (разница в употреблении 84,2\%), “саге” (разница в употреблении 76\%), “deal” (разница в употреблении 72,1\%), “united” (разница в употреблении 69\%), “healthcare” (разница в употреблении 68,4\%). Гистограмма подтверждает нашу гипотезу относительно того, что Дж. Байден моделировал предвыборную риторику в рамках Заботливого Родителя, опираясь на свойственные для этой модели концепты (community, care, united, home). Д. Трамп существенно реже использует концепты, связанные с заботой, семьёй и домом, однако концепт “healthcare” в его речи звучит значительно чаще, чем в речи Дж. Байдена, что подтверждает неизбежные отклонения от приоритетной модели в таком сложном дискурсе, как политический. Также, будучи политиком, имеющим за плечами значительный предпринимательский опыт, Д. Трамп достаточно часто использует свойственные бизнесу концепты “deal” и “dollar”, экстраполируя опыт предпринимательской деятельности на политическую риторику.

Безусловно, победа в предвыборной гонке - сложный и многокомпонентный феномен, зависящий от большого числа как лингвистических, так и социологических факторов (очный или заочный способ голосования, уровень образования избирателей, географическое распределение и так далее). Однако, мы полагаем, что предвыборная речь и её лингвокогнитивные особенности относятся к наиболее значимым факторам, оказывающим большое влияние на реципиента, а значит, на итоги предвыборной гонки.

\section{Заключение}

Таким образом, в рамках проведенного исследования можно сделать следующие выводы:

- к превалирующим моделям современного предвыборного дискурса США следует отнести модели Строгого Отца и Заботливого Родителя;

- качественный и количественный анализ сформированных индивидуальных корпусов концептов, использованных кандидатами на пост президента США в рамках предвыборной кампании 2020 года, показал, что Д. Трамп моделировал свою предвыборную риторику в рамках модели Строгого Отца, в то время как предвыборные выступления Дж. Байдена сформулированы в рамках модели Заботливого Родителя;

- сочетание качественного и количественного анализа превалирующих когнитивных моделей предвыборного дискурса позволило нам осуществить проверку гипотезы о возможном изменении национальных ценностей 
в современном американском обществе. Принимая во внимание тот факт, что в ходе борьбы за пост президента в США в 2016 году на фоне роста экономики победу одержал Д. Трамп, формирующий политическую риторику в рамках модели Строгого Отца (Kasimova, 2020), мы полагаем, что в 2020 году модель Строгого Отца перестала в той же мере отвечать потребностям нации по причине глобального экономического кризиса.

Перспективы дальнейшего исследования мы видим в более детальном изучении лингвокогнитивного моделирования предвыборной риторики США, в частности по таким острым социальным вопросам, как миграционная и налоговая политика.

\section{Источники | References}

1. Баранов А. Н. Предисловие редактора. Когнитивная теория метафоры почти 20 лет спустя // Лакофф Дж., Джонсон М. Метафоры, которыми мы живем. М.: Едиториал УРСС, 2004.

2. Соссюр Ф. де. Курс общей лингвистики / пер. с фр. Екатеринбург: Урал. университет, 1999.

3. Чудинов А. П. Россия в метафорическом зеркале: когнитивное исследование политической метафоры (1991-2000): монография / Урал. гос. пед. ун-т. Екатеринбург, 2001.

4. Штейнман М. А. Матрицы массовой культуры и механизмы создания общности в политическом дискурсе XXI в. // Вестник Российского государственного гуманитарного университета. Серия «Политология. История. Международные отношения». 2012. № 1 (82).

5. Donald Trump Transcripts. 2022. URL: https://www.rev.com/blog/transcript-category/donald-trump-transcripts

6. Joe Biden Speech and Interview Transcripts. 2022. URL: https://factba.se/biden/transcripts

7. Kasimova D. I. Framing within H. Clinton's and D. Trump's Political Discourse. Proceedings of the 12th AllRussian Research and Methodological Conference with International Participation (Moscow, Institute of Foreign Languages, RUDN University, March 27, 2020). Moscow: PFUR, 2020. URL: http://science-ifl.rudn.ru/09835-2020445-454 DOI: $10.22363 / 09835-2020-445-454$

8. Lakoff G. Moral Politics: How Liberals and Conservatives Think. Chicago: University of Chicago Press, 1996.

9. Lakoff G. The Neural Theory of Metaphor // The Cambridge Handbook of Metaphor / ed. by R. Gibbs. N. Y.: Cambridge University Press, 2008.

10. Volkova Y. A. Cognitive Linguoecology as a Methodological Approach to the Study of Destructive Communication // SHS Web of Conferences. 2020. Vol. 88. Iss. 3.

\section{Информация об авторах | Author information}

\section{RU Касимова Диана Ильдусовна ${ }^{1}$ Григорьева Лидия Михайловна ${ }^{2}$}

${ }^{1}$ Российский университет дружбы народов (РУДН), г. Москва

2 Федеральный исследовательский центр «Информатика и управление»

Российской академии наук, г. Москва

EN Kasimova Diana Ildusovna ${ }^{1}$

Grigoryeva Lidia Mikhailovna ${ }^{2}$

${ }^{1}$ The Peoples' Friendship University of Russia (RUDN University), Moscow

${ }^{2}$ Federal Research Center "Computer Science and Control” of the Russian Academy of Sciences, Moscow

${ }^{1}$ kasimova.di@gmail.com, ${ }^{2}$ lidusik777@mail.ru

\section{Информация о статье | About this article}

Дата поступления рукописи (received): 04.12.2021; опубликовано (published): 28.02.2022.

Ключевые слова (keywords): когнитивная лингвистика; политический дискурс; предвыборный дискурс; cognitive linguistics; political discourse; electoral discourse. 